\title{
Prospective mathematics teachers' self-referential metaphors as indicators of the emerging professional identity
}

\author{
Päivi Portaankorva-Koivisto ${ }^{1}$ and Barbro Grevholm² \\ ${ }^{1}$ University of Helsinki, Finland \\ ${ }^{2}$ University of Agder, Norway and Kristianstad University, Sweden
}

Ideals play a key role in a student teachers' identity work. They form targets to strive for and a mirror for reflection. In this paper, we examine Finnish mathematics student teachers' metaphors for the teacher's role ( $N=188)$. We classified the metaphors according to a model that identified teachers as subject matter experts, didactical experts, and pedagogical experts, with the addition of another two categories, self-referential and contextual. For the exploration of emerging professional identities, we studied the self-referential metaphors, which formed the most common category in the data. We observed that every third metaphor described either student teachers' personalities or their incompleteness as teachers, or new beginnings or eras. Although these aspects were expected, they also inform us as teacher educators of the values and ideals that student teachers have in terms of teaching and being a teacher. The metaphors that mathematics student teachers produced illustrated their identity processes and their emerging identity as a mathematics teacher.

\author{
Keywords \\ metaphors, \\ teacher's role, \\ student teachers, \\ mathematics education \\ Correspondence \\ paivi.portaankorva- \\ koivisto@helsinki.fi \\ DOI \\ https://doi.org/10.31129/ \\ LUMAT.7.2.343
}

\section{Introduction and purpose of the study}

In teacher education, prospective teachers' teacher identity is considered a complex and dynamic construction in which personal and professional features complement each other (Beijaard, 2017). Student teachers ponder questions such as: "Who am I as a teacher or what kind of teacher do I want to become?” (Beijaard \& Meijer, 2017). Ideals play a significant role in an individual's identity work because they form targets to strive for and help set goals. Ideals reflect what is valued (Poom-Valickis \& Löfström, 2018), but if they conflict with reality, they come under doubt (Anspal, Leijen, \& Löfström, 2018).

Beijaard and Meijer (2017, p.178) state that beliefs are the building blocks of a teacher's professional identity because they guide teacher's engagement, commitment and actions both in and out of the classroom (see also Vermunt, Vrikki, Warwick, \& Mercer, 2017). Cross (2017) describes teacher identity as both a process and a product, a relationship between people and professional contexts, socially situated and differentiated from a teacher's role, but not clearly differentiated from a teacher's self. 
Ketelaar, Beijaard, Boshuizen, and Den Brok (2012) studied eleven teachers' positioning regarding educational innovations, and their findings showed that three concepts were useful for describing the similarities and differences in teachers' positioning, namely ownership, sense-making, and agency. Ownership acts as a facilitator when expressing who one is as a teacher. Sense-making is about the interaction between one's identity and what one is striving for, resulting in maintenance or change in one's identity. Agency in turn gives the teaching career a direction. Most teachers, particularly in secondary and higher education, derive their identity first and foremost from the subject they studied themselves (Beijaard, 2017). Thus, it is important that student teachers can experience autonomy during teacher education and have space for negotiation about both their former and their emerging intentions (Beijaard \& Meijer, 2017). Moreover, they must have the opportunity to participate authentically as teachers, which means that they must have autonomy and responsibility for others as well as themselves (Moate \& Ruohotie-Lyhty, 2014).

Different practical methods have been used in teacher education to support student teachers' identity work. Bullough (2015) listed several: life writing autobiographies and life histories, journals, diaries, blogs, logs, and scenarios. Moate and Ruohotie-Lyhty (2014) mentioned action research, teachers' auto-biographical stories, and the use of metaphors. A recent study by Hamilton (2016) offered prospective teachers opportunities to consider and articulate metaphorical ideas through multimodal means by taking pictures. Lynch and Fisher-Ari (2017) collected periodic metaphors. Their students wrote a metaphor after every class and saved the series of metaphors on Padlet-boards (padlet.com). Tait-McCutcheon and Drake (2016, p.1) asked their participants to draw metaphorical pictures of jackets: 'Imagine for a moment that the relationship between yourself and your professional learning and development is a jacket. What jacket would it be and how would you wear it?'.

In this paper, we examine prospective mathematics teachers' metaphors for the teacher's role. We used the same Manual as was used for the NorBa Project (Löfström, Poom-Valickis, \& Hannula, 2011), which is based on Beijaard, Verloop, and Vermunt's (2000) tripartition of teachers as subject matter experts, didactical experts, and pedagogical experts, expanded with two additional categories, self-referential and contextual. Our definition of the concept of metaphors is this:

A metaphor is 'an application of a word or a phrase to an object or concept it does not literally denote, suggesting a comparison to that object or concept' (Random 
House Webster's College Dictionary, 1990). A metaphor is most often a noun, and common categories are an inanimate or animate object, a person, or an animal.

In this study, we concentrated on student teachers' self-referential metaphors which comprised the most common category in our data, and our research questions were:

1. "What self-referential metaphors do the prospective mathematics teachers use most often: inanimate objects, animate objects, persons or animals?"

2. "What aspects of prospective mathematics teachers' emerging professional identity can be traced from self-referential metaphors?"

\section{Metaphors in teacher education}

Kasoutas and Malamitsa (2009) stated that metaphors are valuable in teacher education because they elicit teachers' personal theories of learning and teaching. They also identified three reasons for using metaphors: (1) they enable us to express things and ideas that are difficult to describe through literal language, (2) they capture the complexity and multiplicity of our experiences and ideas, and (3) they are more concise and vivid than literal language. For many prospective teachers, as well as for in-service teachers, metaphors offer insights into the ways in which teachers may understand themselves and their actions in the class (Thomson, 2015).

By using metaphors, prospective teachers can articulate their understanding of complex ideas and concepts regarding teaching and learning. Metaphors also serve as tools for fresh perspectives on experience, new ways for making meaning, and reflection (Bullough, 2015; Hamilton, 2016). Lynch and Fisher-Ari (2017) describe metaphor creation as innovative and rooted in linguistic and conceptual forms. According to them, metaphors serve both literary and aesthetic purposes.

In teacher education, metaphors can mediate the relationship between espoused beliefs and enacted practice and provide potential for changing both (TaitMcCutcheon \& Drake, 2016). Therefore, prospective teachers can apply metaphors when exploring, examining, and understanding their own emerging professional identities (Hamilton, 2016).

Sometimes people feel more comfortable when they can disguise their thoughts using metaphors. Tait-McCutcheon and Drake (2016) found in their study that lead teachers willingly used third person positioning and humour. This enabled them to be 
more honest and authentic with their reflections. For teacher educators, metaphors can serve as a method to trail students' engagement, to notice students who need additional support, or to picture a more holistic knowledge of individual students. (Lynch \& Fisher-Ari, 2017).

\section{Metaphors for the teacher's role}

At the beginning of their professional growth, prospective teachers tend to focus on themselves. They still lack experience for wider understanding of teacher roles, membership in school organizations, collegial co-operation, and learning. PoomValickis and Löfström (2018) noticed that student teachers had doubts about possessing the qualities and skills necessary for a teacher. They wondered whether they were clever enough, or able to present their case or manage a class. Some students also wondered whether they had made the right career choice. In her study, Hamilton (2016) found three themes, namely teacher and teaching as guide and guiding, teacher dispositions, and the multiplicity of teaching. During teacher education student teachers also changed the metaphors they had chosen in the beginning of their studies. Löfström and Poom-Valickis (2013) found that a third of the metaphors stayed the same, another third changed completely, and in the rest of the cases some element was added to the initial idea which expanded the view of the teacher's role.

Löfström, Poom-Valickis, and Hannula (2011) have developed a manual for analysing teacher metaphors. They identified five categories: (1) subject matter experts, (2) didactical experts, (3) pedagogical experts, (4) self-referential metaphors, and (5) contextual metaphors. Subject matter experts possess vast, detailed knowledge which they transmit to their pupils. Didactical experts know how to split the content into comprehensible parts and how to facilitate pupils' learning. Pedagogical experts focus on caring and nurturing pupils' holistic development. Selfreferential metaphors indicate the characteristics of the teacher's personality, personal characteristics or features (c.f. Portaankorva-Koivisto, 2013). And finally, contextual metaphors describe where or in what kind of setting or environment the teacher works.

An earlier study examined Finnish pre-service and in-service mathematics teachers' metaphors for the teacher's role (Oksanen, Portaankorva-Koivisto, \& Hannula, 2014). The most common metaphor category $(46 \%, 33 / 81)$ used among pre- 
service mathematics teachers was self-referential, in comparison to in-service teachers, of whom only 15\% (10/94) presented a self-referential metaphor. As their analysis progressed, Oksanen et al. (2014) noticed that self-referential metaphors could be further classified into four different subcategories. Metaphors describing personality or characteristics (24\%), metaphors describing hesitation (33\%), metaphors describing a new beginning or new era (18\%), and metaphors describing something 'big' waiting ahead (24\%).

Interestingly, a group of experienced teachers in Norway rarely used selfreferential metaphors (Grevholm, 2018). Only about one out of six teachers gave a self-referential answer, which is in line with the findings of Oksanen, PortaankorvaKoivisto, and Hannula (2014) mentioned above. Some such examples were an actor and a midwife, who are qualified, experienced, professionals. Other examples were a rock in an agitated sea, or a potato. The idea of the potato seems to be rooted in a specific Norwegian saying which claims that a potato is very useful and can be of help in many different situations (used in many dishes).

\section{The study and its methodology}

\subsection{Context}

Secondary teacher education in Finland consists of a five-year programme (3 BSc and 2 MSc, 300 ECTS). The students major in one school subject and minor in one or two others. Prospective mathematics teachers have pedagogical studies (6o ECTS) as a minor subject which can be completed in one academic year. At the University of Helsinki, these studies include 20 ECTS of supervised teacher training in university teacher training schools, 17 ECTS courses in general education, 15 ECTS didactical courses in students' major and minor subjects, and 8 ECTS of students' pedagogical thesis. Pedagogical studies combined with subject studies provide qualifications to teach at the secondary level.

\subsection{Participants and data collection}

The data for this study was collected at the University of Helsinki at the end of student teachers' pedagogical studies, in 2012-2016. Mathematics student teachers were asked to write a metaphor and expand the statement 'as a mathematics teacher I am ..., and to continue with an explanation for their statement. We only gathered the 
metaphors for which students had granted permission to use as data. All in all, 188 metaphors were collected.

\subsection{Analysis and data selection}

The analysis can be seen as a deductive content analysis with the given categories mentioned above. Metaphors were categorized on a case-to-case basis, using two independent raters, the coding of which were compared at the end. In contradictory cases, a third rater was used. The metaphors and their explanations were analysed as a unit. Sometimes the metaphor was unambiguous and in line with the explanation, and sometimes it could be used to express different meanings and the explanation became firmer. Metaphors that had no explanation at all were excluded. After categorization, only the metaphors categorized as self-referential were selected for further analysis. These 67 metaphors $(36.4 \%$ of the total 184 metaphors with explanations) made up the data for this study. In some cases, students replied with something that could be literally true (e.g. "myself"), in which case the answer was excluded. One reason for the focus on self-referential metaphors is that these metaphors focus mainly on what teaching represents for the students as individuals. They describe features or characteristics of the teachers' personality. The metaphors describe who the teacher is, part of the teachers' identity. And our interest in this paper is the emerging teacher identity. A second reason is that according to the earlier study by Oksanen et al. (2014) mentioned above, the self-referential metaphors are specific to pre-service teachers. Therefore, they are important to study in detail. A third reason is that the rest of the metaphors are analysed as a basis for other papers.

\section{Analysis and findings}

First, we analysed mathematics student teachers' self-referential metaphors according to the metaphor words they had used. The student teachers in this study most often used an inanimate object (26 items) such as a rainbow, a ship in the fog, a diary, or red wine, or a person (20 items) such as a Buddhist monk. Less common was the category of animate object (10 items) such as a seed or a bun dough or an animal (8 items), such as a young foal, or "my dog Karu". Thus, 26 metaphors represent static objects and 38 metaphors (59.4\%) refer to a changing situation.

Second, we analysed the metaphors and their explanations and looked for their meaning. We divided them into three categories. About $40.3 \%$ were metaphors 
describing the student teachers' personalities, and 40.3\% described incompleteness as a teacher. The third, and smaller category, $10.4 \%$, were metaphors describing a new beginning or era.

Cross-tabulation revealed that the metaphor's word analysis could not describe the whole meaning of the metaphor. When the student teachers used inanimate objects as metaphor words, they could express either their personality or their incompleteness as a teacher.

Inanimate objects describing personality:

"As a mathematics teacher, I am a rainbow full of a beautiful spectrum of colours that bring diversity and joy but are still in a certain order and bring similarity."

"As a mathematics teacher I am a circle because I am soft and friendly."

"As a mathematics teacher I am a clock - precise."

Inanimate objects describing incompleteness as a teacher:

"As a mathematics teacher I am a log cabin under construction, the foundations and building blocks are a solid piece of work, but it takes a lot of time to get it ready. And indeed, cottage projects are such lifelong projects, they can never be fully ready."

"As a mathematics teacher I am a prototype, not yet ready but a model that needs to be refined and developed over and over again."

"As a mathematics teacher I am a product or service, formally ready, yet something to be further developed."

When describing their personality as a teacher, student teachers often referred to characteristics that they expected teachers to require, such as calmness, friendliness, or creativeness. They also reflected on their capabilities and pondered if they had already forgotten what was difficult in learning elementary mathematics or how they could remember their pupils' names.

Animate objects describing personality:

"As a mathematics teacher I am a calm sea, I am a very calm person, but I recognize the potential power within me (authority)." 
"As a mathematics teacher I am an onion, because I have acquired a lot of experience in how to apply mathematics and at the same time, I have forgotten how it all started."

An animal describing personality:

"As a mathematics teacher I am a fox, I rely more on intelligence and wisdom than learning by heart."

"As a mathematics teacher I am a cat, always curious and enthusiastic with delicious ideas."

"As a mathematics teacher I am my dog Karu, who gets excited about new things and is fine with people."

\section{A person describing personality:}

"As a mathematics teacher I am a Buddhist monk, while I teach mathematics, I am rather quiet and reflective not the 'let's get going' type of person."

“As a mathematics teacher I am Charlie Parker, I do not play notes.”

"As a mathematics teacher I am an Alzheimer patient, I do not remember anyone's name and constantly demand reasons for everything."

When describing incompleteness, student teachers often referred not to their new identity as a teacher but to the fact that teachers must develop their work throughout their careers.

Animate objects describing incompleteness as a teacher:

"As a mathematics teacher I am a newly planted tree, I have every opportunity to grow into a tall and solid tree if I get help and support when I have difficult times. In other words, I still need help and support as a mathematics teacher.”

"As a mathematics teacher I am a crocus that blossoms in early spring. I'm trying persistently to develop and 'flourish' as a teacher, but still need time.”

"As a mathematics teacher I am a banana, at first, I might seem a bit raw, but I will mature over time."

\section{An animal describing incompleteness as a teacher:}

"As a mathematics teacher I am a foal who is learning to walk, and every day gets more self-confident and more robust, I have little experience in teaching, but every lesson I learn new things to improve my following lessons." 
"As a mathematics teacher I am a new-born lamb, I can get up, that means I have the basic skills, but I am still a bit unsteady and there is a lot to be learned."

"As a mathematics teacher I am a butterfly chrysalis, the caterpillar phase lasted from the day I was born until the beginning of my pedagogical studies. Now I'm in the housing phase where I still have a lot to develop, and maybe one day I will be a teacher, a butterfly, even though the teacher develops throughout his life."

Here the choice of the animal, in a developing phase or young and new, transmits the image of incompleteness.

A person describing incompleteness as a teacher:

“As a mathematics teacher I am a small child, helpless but eager to learn.”

"As a mathematics teacher I am a child taking his first steps. I feel I'm not ready to teach or to go back to school again. If I ever become a teacher, I must first find an awful lot of self-confidence and confidence in my own skills. And if (or when?) this happens, who knows what will happen. But I still need support."

"As a mathematics teacher I am a little child inspired to learn new things."

Again, the choice of metaphor word, indicating something young and new-born, exposes an image of the start of building a teacher identity.

Every tenth metaphor described a new era or new beginning. Sometimes student teachers embraced it and saw their role as valuable. Sometimes they felt uncertain and hesitated about whether they wanted to become teachers at all.

"As a mathematics teacher I am a hiker who has serviced his bicycle, ready for a longer trip.”

"As a mathematics teacher I am a glue stick, everything sticks, but I can pull my head in and hide."

"As a mathematics teacher I am only a puppy, growing up as a teacher, but willing to learn new things."

"As a mathematics teacher I am an autumn leaf on the wind, let's see where I'm going."

"As a mathematics teacher I am a ship in the fog which I hope finds its way to the harbour."

"As a mathematics teacher I am a flame that lights the candle, because there is no better lighter than a man who has fought against the same wind." 
"As a mathematics teacher I am a long-distance relay runner who has received a baton from his teachers."

Here the chosen metaphor words are dynamic and indicate new changing situations. The student teachers sense a new beginning of a process that will develop and mature.

\section{Discussion}

Teacher identity is both a process and a product (Cross, 2017). This was confirmed by the answers of the mathematics student teachers in our study in Finland. For example, the teacher is seen as a final product in the metaphors of a rainbow, a circle, and a clock. On the other hand, the teacher is seen as a process in the metaphors of a log cabin under construction, a prototype, a crocus, or a newly planted tree. The product cases descriptions of teacher ideals or desired characteristics for the future were, for example, bringing diversity and joy, being soft and friendly, and being precise. The ideals reflect what is valued (Poom-Valickis \& Löfström, 2018) and strongly point to the future as a teacher.

In the process cases we found links to teacher development over time: building blocks being solid pieces, but the building of a cabin being a life-long project; a prototype that needed to be repeatedly developed and refined; a crocus persistently trying to develop and 'blossom' as a teacher, but still needing time; a newly planted tree that would grow into a tall and solid tree if it receives help when needed.

The answer to our first research question is that six out of ten students chose a dynamic word when describing the teacher's role: a live object, a person, or an animal. That could be interpreted as if they are having a sense of the changing situation as prospective teacher. The second question searches the answer to what aspects of emerging teacher identity can be found. One of the aspects is that the student teacher is taking part of a process, is developing and growing, maturing and getting more complete. The student can sense the new beginning or start of a learning process. Some realize that the learning process as teacher is life-long. Another aspect is that students give hints about how they see ideal teaching and learning, for example rather using wisdom and intelligence than learning by heart, rather teaching in a quiet and peaceful way than in 'let us get going style'. The metaphors also reveal many 
personality traits that are seen as valuable, such as helpful, kind, humoristic, willing, improving, and so on.

According to Kasoutas and Malamitsa (2009), metaphors are valuable in teacher education because they elicit teachers' personal theories regarding learning and teaching. For example, in the metaphor of a fox, the student's theory is that it is more important to rely on intelligence and wisdom than learning by heart. In the case of the Buddhist monk the student seems to believe in teaching in a quiet and reflective way rather than being the 'let's get going' type of teacher. The students' own learning is illustrated by the metaphors. An example is the foal, which is learning to walk and becoming more self-confident and stable; or the puppy, which is still growing as a teacher but willing to constantly learn.

We found that it was much more common for student teachers to use selfreferential metaphors than it was for experienced teachers. This result coincides with the study by Oksanen et al. (2014) and observations by Grevholm (2018). In our study almost every third student teacher chose a self-referential metaphor. Among those who used self-referential metaphors, about four out of ten used metaphors describing student teachers' personalities or characteristics. Four out of ten used metaphors describing their incompleteness as teachers. One out of ten preferred metaphors describing a new beginning or era.

The results were not surprising. It is understandable that prospective teachers focus on teacher personality or identity and on their own incompleteness as teachers. During their education, they are reminded of the preferred characteristics of teachers and what they themselves must develop in order to achieve the goal of becoming a 'good' teacher. More experienced teachers have a deeper understanding of teachers' working conditions and contexts, and they can relate better to phenomena other than the self. They have a wider view of the profession. The use of metaphors to describe the teacher's role helped make these differences between experienced teachers and student teachers visible. The metaphors also illustrated and indicated some aspects of what prospective teachers saw as professional development for teachers. One of these aspects was the willingness to learn, while understanding that a teacher is a life-long learner, patient, soft, friendly, calm, joyful, self-confident, knowing, and able to withstand hard use when needed. 


\section{References}

Anspal, T., Leijen, Ä., \& Löfström, E. (2018). Tensions and the teacher's role in student teacher identity development in primary and subject teacher curricula. Scandinavian Journal of Education, 1-17. https://doi.org/10.1080/00313831.2017.1420688

Beijaard, D. (2017). Learning teacher identity in teacher education. In D. J. Clandinin, \& J. Husu (Eds.), The SAGE handbook of research on teacher education (pp. 139-142). London, England: Sage.

Beijaard, D., \& Meijer, P. (2017). Developing the personal and professional in making a teacher identity. In D. J. Clandinin, \& J. Husu (Eds.), The SAGE handbook of research on teacher education (pp. 177 - 192). London, England: Sage.

Beijaard, D., Verloop, N., \& Vermunt, J. D. (2000). Teachers' perceptions of professional identity: an exploratory study from a personal knowledge perspective. Teaching and Teacher Education, 16(7), 749-764. https://doi.org/10.1016/So742-051X(00)00023-8

Bullough, R. V. (2015). Methods for studying beliefs: Teacher writing, scenarios, and metaphor analysis. In H. Fives, \& M. G. Gill (Eds.), International handbook of research on teachers' beliefs (pp. 150-169). New York; NY: Routledge.

Cross, B. (2017). Teacher education as a creative space for the making of teacher identity. In D. J. Clandinin, \& J. Husu (Eds.), The SAGE handbook of research on teacher education (pp. 210-227). London, England: Sage

Grevholm, B. (2018). Teacher metaphors in Norway. Internal report to the NORBA-group. Tallinn, 20180313.

Hamilton, E. R. (2016). Picture this: Multimodal representations of prospective teachers' metaphors about teachers and teaching. Teaching and Teacher Education, 55, 33-44. https://doi.org/10.1016/j.tate.2015.12.007

Kasoutas, M., \& Malamitsa, K. (2009). Exploring Greek teachers' beliefs using metaphors. Australasian Journal of Teacher Education, 34(2), 64-83.

Ketelaar, E., Beijaard, D., Boshuizen, H. P., \& Den Brok, P. J. (2012). Teachers' positioning towards an educational innovation in the light of ownership, sense-making and agency. Teaching and Teacher Education, 28(2), 273-282.

https://doi.org/10.1016/j.tate.2011.10.004

Lynch, H. L., \& Fisher-Ari, T. R. (2017). Metaphor as pedagogy in teacher education. Teaching and Teacher Education, 66, 195-203. https://doi.org/10.1016/j.tate.2017.03.021

Löfström, E., Anspal, T., Hannula, M. S., \& Poom-Valickis, K (2010). Metaphors about 'the teacher': Gendered, discipline-specific and persistent? In J. Mikk, M. Veisson, \& P Luik (Eds.), Teacher's personality and professionalism. Estonian Studies in Education (pp. 105-122). Frankfurt am Main, Germany: Peter Lang.

Löfström, E., \& Poom-Valickis, K. (2013). Beliefs about teaching: Persistent or malleable? A longitudinal study of prospective student teachers' beliefs. Teaching and Teacher Education, 35, 104-113. https://doi.org/10.1016/j.tate.2013.06.004

Löfström E., Poom-Valickis K., \& Hannula M. S. (2011). Categorisation of teacher metaphors. Unpublished manual for the NorBa Project. University of Helsinki and Tallinn University.

Moate, J., \& Ruohotie-Lyhty, M. (2014) Identity, agency and community: reconsidering the pedagogic responsibilities of teacher education, British Journal of Educational Studies, 62(3), 249-264. https://doi.org/10.1080/00071005.2014.955456

Oksanen, S., Portaankorva-Koivisto, P., \& Hannula, M.S. (2014). Teacher metaphors - differences between Finnish in-service and pre-service mathematics teachers. In P. Liljedahl, C. Nicol, 
S. Oesterle, \& D. Allan (Eds.), Proceedings of the joint meeting of PME 38 and PME-NA 36 (Vol. 4, pp. 361-368). Vancouver, Canada: PME.

Poom-Valickis, K., \& Löfström, E. (2018). "Pupils should have respect for you, although I have no idea how to achieve this?": The ideals and experiences shaping a teacher's professional identity. Educational Studies, 45(2), 1-18.

https://doi.org/10.1080/03055698.2018.1446323

Portaankorva-Koivisto, P. (2013). Prospective mathematics teachers' metaphors for mathematics, teaching, and the teacher's role. Nordic Studies in Mathematics Education, 17(3-4), 159176.

Random house Webster's college dictionary (1990). New York, NY: Random House.

Tait-McCutcheon, S., \& Drake, M. (2016). If the jacket fits: A metaphor for teacher professional learning and development. Teaching and Teacher Education, 55, 1-12.

Thomson, M. M. (2015). Metaphorical images of schooling: Beliefs about teaching and learning among prospective teachers from the United States displaying different motivational profiles. Educational Psychology, 36(3), 1-24. https://doi.org/10.1080/01443410.2015.1024612

Vermunt, J.D., Vrikki, M., Warwick, P., \& Mercer, N. (2017). Connecting teacher identity formation to patterns in teacher learning. In D. J. Clandinin, \& J. Husu (Eds.), The SAGE handbook of research on teacher education (pp. 143-159). London, England: Sage. 